\title{
Characteristic Curve of the Relation of Cutting Conditions and the Results of Metal Machining
}

Karol Vasilko, Zuzana Murčinková

Faculty of Manufacturing Technology Technical University of Košice, 08001 Prešov, Bayerova 1, E-mail: karol.vasilko@tuke.sk, zuzana.murcinkova@tuke.sk

Metal machining is a complex technological process based on material removal from semi-product by the influence of a cutting tool which is abrasion-resistant at high mechanic and heat strain. The essence of material removal is based on considerable material plastic deformation under the tool cutting wedge, the result of which is a deformed chip and transformed workpiece surface, which must comply with the geometrical and mechanical workpiece characteristics. These are determined by selected cutting conditions, geometrical and mechanical characteristics of the cutting tool. The selection of cutting conditions is engineering art and requires deep knowledge of machining process, mainly the relationship between cutting conditions and their results of machining. These relationships are being tried to identify in the paper.

Keywords: machining, cutting, forces, cutting surface quality, tool life

\section{Introduction}

To determine optimal cutting conditions it is necessary to exactly know their influence on the results of machining. Metal machining possesses stochastic character, therefore to determine reliable conclusions it is needed to perform a statistically meaningful number of experiments to determine the relationships between the cutting conditions and results of machining. Basic parameter, which extensively influences the output parameters of machining (cutting forces, quality of machined surface, tool durability) is cutting speed. The paper tries to experimentally and exactly identify its importance and influence on presented technological characteristics of the machining process.

\section{Cutting forces}

Fig. 1 shows the size of specific cutting force depending on cutting speed for medium-rigid steel.

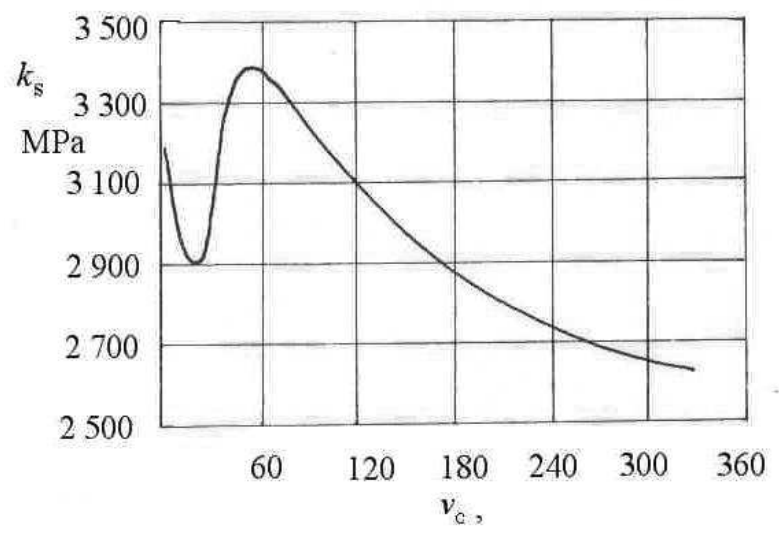

Fig. 1 Change of specific cutting force with cutting speed (cut material C45); cutting conditions identical with Fig.1.2.
The dependence of actual cutting forces on cutting speed will therefore have the same character. Fig. 2 displays such experimental dependence.

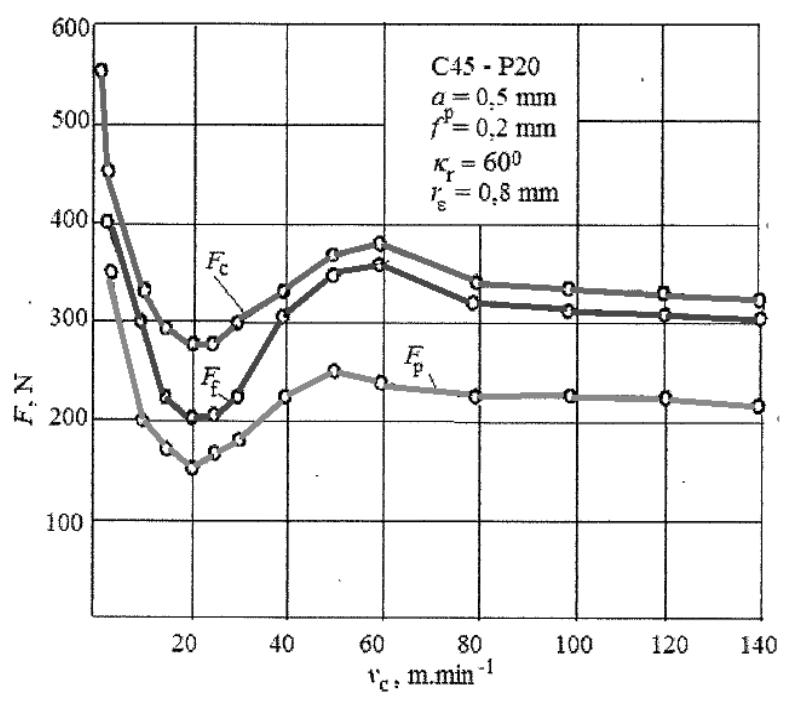

Fig. 2 Experimental dependence $F\left(v_{c}\right)$

It can be seen that cutting speed does not have influence on mutual ratio of cutting forces, only their absolute value. The curve course $F\left(v_{c}\right)$ can be explained in physics way as follows: at low cutting speeds, the material is practically machined by the environment temperature. Its rigidity corresponds with the chart value, therefore it resists a lot when the tool cutting wedge enters. Both measuring and concrete cutting forces are high. Increase of cutting speed leads to material heating in front of the cutting wedge, which means the decrease of cutting resistance [1], [4]. 
Cutting forces decrease rapidly. However, it is known that material rigidity, depending on the heating temperature, does not have a linear course [10]. The following curves have been obtained in strength test by elongation - Fig. 3 .

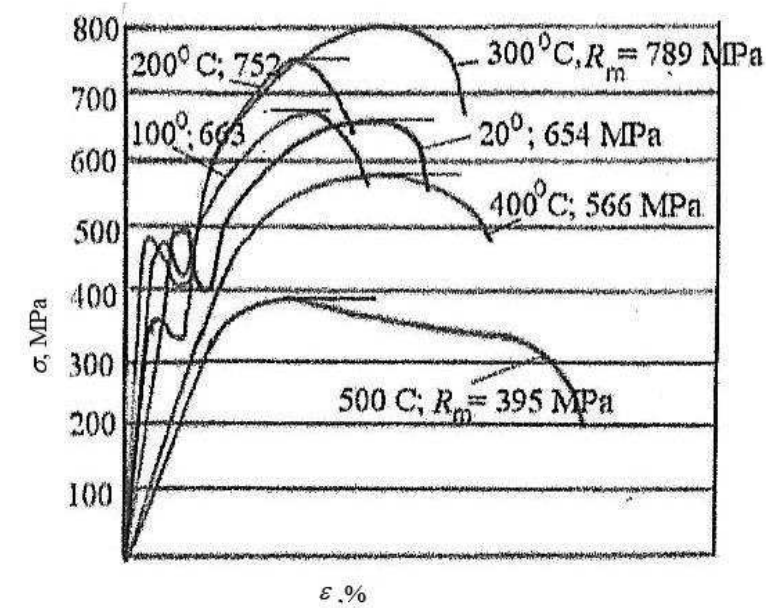

Fig. 3 Dependence between stress and sample extension at elongation and heating test

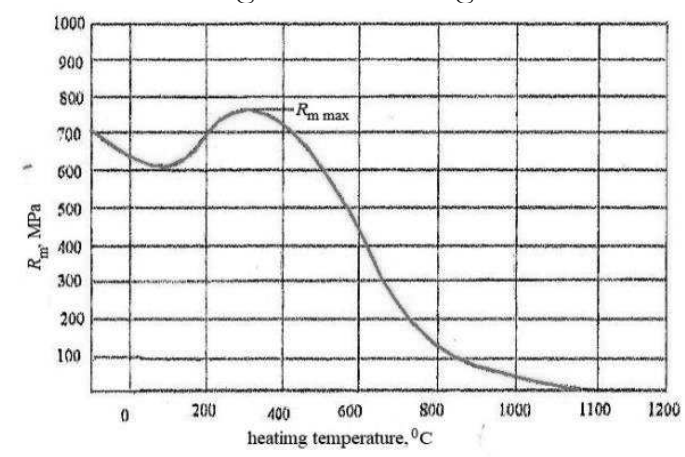

Fig. 4 Derived dependence between strength in elongation and sample temperature

That is where the dependence of strength in elongation on the actual temperature of heating can be derived, see Fig. 4.

As it can be seen, the limit of steel strength gradually increases up to the temperature $300^{\circ} \mathrm{C}$, when material relaxation occurs. The temperature which is created in front of the tool cutting wedge, as a result of the deformation and friction between the cut and cutting materials, is directly proportional to cutting speed. With a degree of certainty, it can be said that $\theta_{r}\left({ }^{0} C\right) \approx 10 \cdot v_{c}\left(m \cdot \mathrm{min}^{-1}\right)$. Higher strength also means higher measurable cutting force and the different character of chip plastic deformation. Adhesion forms between the chip and tool face. This might be the reason why a built-up edge is formed on the cutting wedge.

\section{Chip compression}

It is defined as the ratio of mean chip thickness $h_{1}$ and the thickness of cut-off chip $b$ :

$$
k=\frac{h_{1}}{h} .
$$

As the determination $b_{1}$ with a segmented chip might be problematic, a more precise methodology to determine it has been used. A recorded chip of known length is considered and at a defined density of cut material, $k$ is calculated with the help of the following:

$$
k=\frac{1000 \cdot m_{1}}{l_{1} \cdot \gamma \cdot S}
$$

where $m_{1}$ is weight of chip with length $h_{1}, \mathrm{~g}$,

$\gamma$ - cut material density, g.cm ${ }^{-3}$,

$S$ - area of cut cross-section $\left(a_{\mathrm{p}} \mathrm{x}\right)$ ),

Fig. 5 evaluates the experimental dependence of chip compression on cutting speed

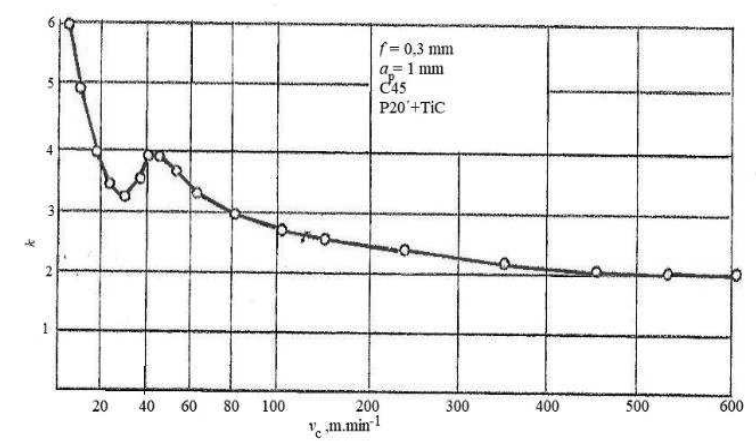

Fig. 5 Experimental dependence between chip compression and cutting speed

\section{Quality of machined surface}

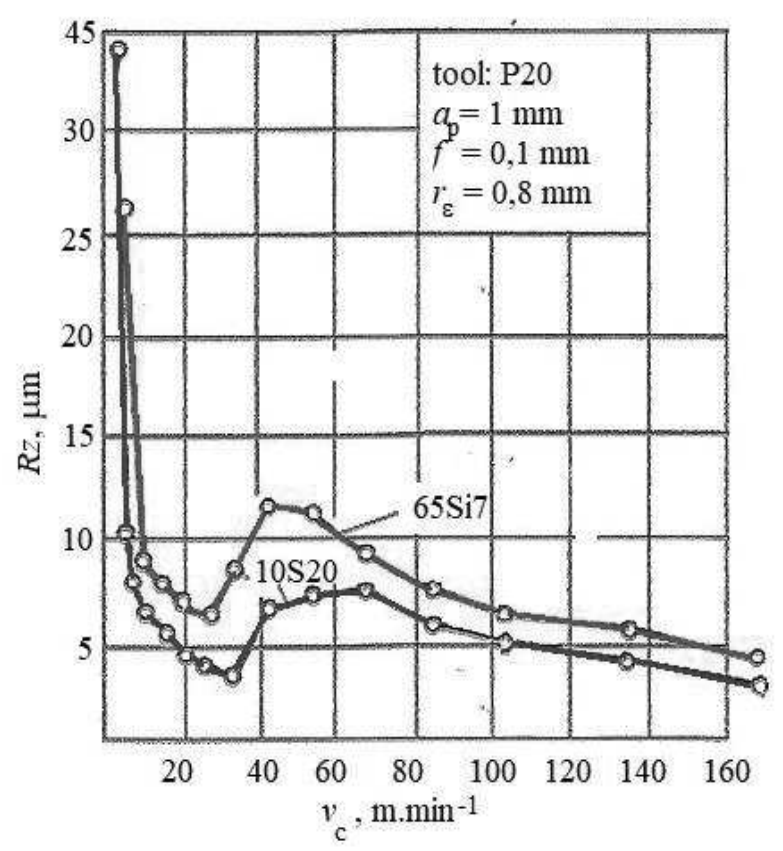

Fig. 6 Experimental dependence of the elements of cutting force on cutting speed 
The character of chip plastic deformation and machined surface has, at increasing cutting speed, a considerable influence on the geometric shape of unevenness on workpiece machined surface [1], [6]. Extensive experiments to determine $R_{z}\left(v_{c}\right)$ have been performed. One of them, obtained during workpieces made of two low-carbon steels turning, is shown in Fig. 6.

Fig. 7 shows a similar dependence, made at finishing turning from a large number of experiments. The character of the curve course is identical. The dispersion of measured values at different cutting speeds is almost identical as well.

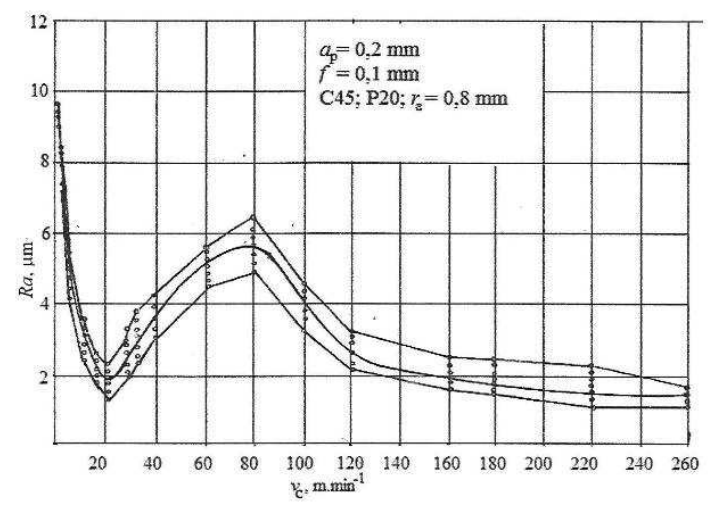

Fig. 7 Experimental curve of dependence $\mathrm{R} a\left(v_{c}\right)$, obtained from a statistically meaningful number of measurements.

The logic of such course is based on the following: Fissure-creating process at the formation of the chip and machined surface is at work in the area of minimal cutting speeds. Surface unevenness elements are high. However, they gradually decrease in the process of heating and increasing the plasticity of cut material. Minimal unevenness is created at cutting speed around $20 \mathrm{~m} \cdot \mathrm{min}^{-1}$. Next, under the influence of adhesion between cut and cutting materials, the unevenness of machined surface increases, up to cutting speed around $80 \mathrm{~m} \cdot \mathrm{min}^{-1}$, when the built-up edge classes to be formed. Highly heated surface of cut material „smooths" out and the unevenness of machined material continually decreases.

\section{Cutting tool durability}

Historically, evaluation of tool durability according to Taylor equation, remains, it means that also experimental dependence $T\left(v_{c}\right)$, which has been by simplification approximated to a line [3], [5] in a double logarithmic net. Recent considerable improvement of cutting tools, softening of the grains of sintered carbide, complex tool coating, have led to the increase of cutting speed and the need to re-evaluate this classical equation. The paper tried to design a detailed course of dependence $T-v_{\mathrm{c}}$ in a wide range of cutting speeds.
A detailed experimental dependence $V B-\tau_{\mathrm{s}}$ is the base, see Fig. 8.

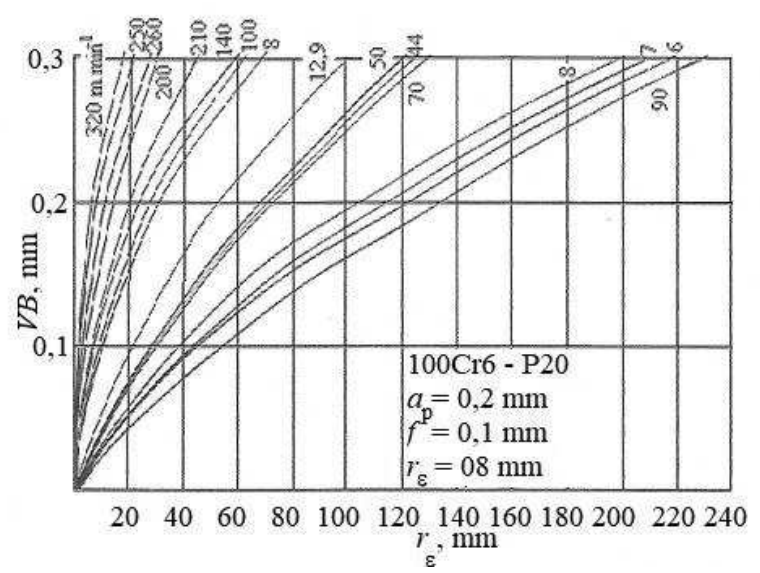

Fig. $\boldsymbol{8}$ Experimental dependences $V B=f\left(\tau_{s}\right)$, obtained in a wide range of cutting speeds

For the blunting criterion $\mathrm{VB}_{\mathrm{k}}=0.3 \mathrm{~mm}$, dependence $T-v_{c}$ has been designed, see Fig. 9.

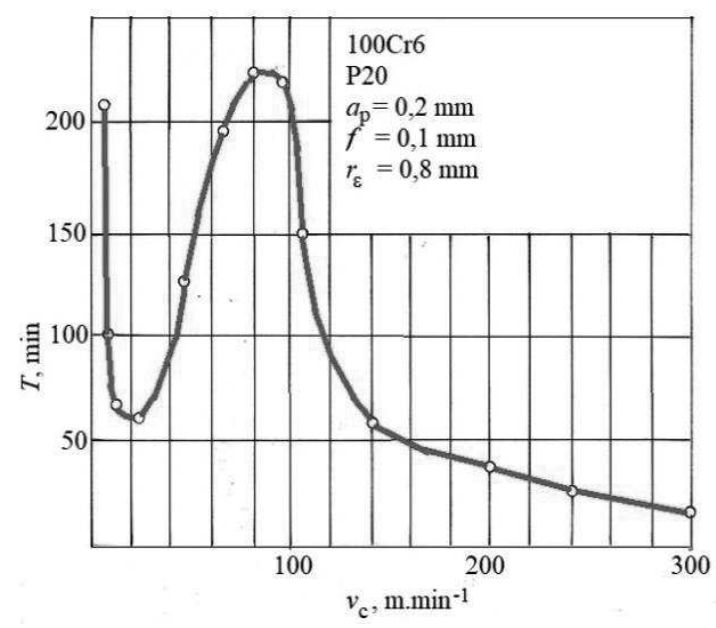

Fig. 9 Experimental dependence of tool durability on cutting speed at turning by a tool made of sintered carbide in a linear coordinate system.

It can be seen that the curve course is rather complex and communicates with the curve courses shown in Fig. 1, 2, 4, 5, 6 and 7. This implies a conspicuous common law. If this dependence is transformed into a double logarithmic system (Fig. 10) according to Taylor, a graph which can be interpolated by abscissa. When Taylor principle was tried to be applied, it can be stated that it is valid only for the cutting speed above $80 \mathrm{~m} \cdot \mathrm{min}^{-1}$, where it can be described by the following relation: $T=\frac{C_{\mathrm{T}}}{v_{\mathrm{c}}^{\mathrm{m}}}$. However, it is necessary to realise that recently a whole range of cutting speeds is being used (cutting-off, drilling, turning with complex tools), where the tool durability, considering Fig. 9 , changes a lot. 


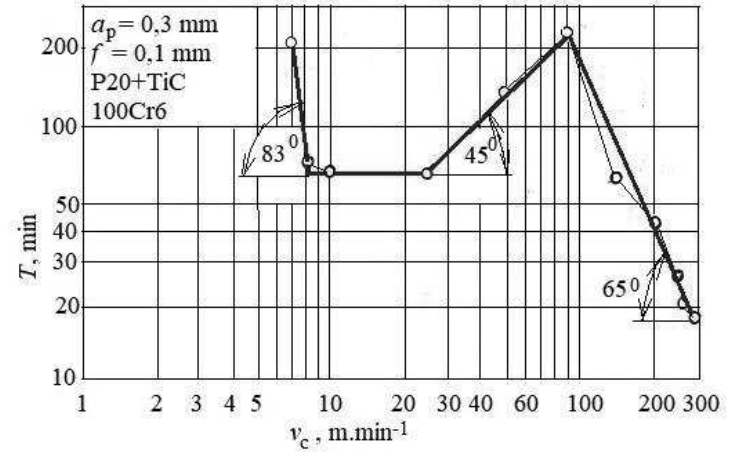

Fig. 10 Dependence from Fig. 9 in a double-logarithmic coordinate system

In a classic Taylor equation, the presented angles would lead to the values of $\mathrm{m}$ :

$85^{0}-\mathrm{m}=6,25 ; 45^{0}-\mathrm{m}=1 ; 65^{0}-\mathrm{m}=2,3$.

For the interest sake, similarly obtained curves $\mathrm{T}$ $\mathrm{v}_{\mathrm{c}}$ in maximum reachable range of cutting speeds have been obtained.

In Fig. 11 there is an experimental dependence $\mathrm{T}$ $\mathrm{v}_{\mathrm{c}}$ on cutting speed $1400 \mathrm{~m} \cdot \mathrm{min}^{-1}$, for machining with a tool with TiN abrasion-resistant coating. The course on the left is practically identical to the course in Fig. 8. When the cutting speeds are increased up to extreme values, the tool durability continually decreases and reaches values of several seconds. These such cutting speeds do not have any justification in practice.

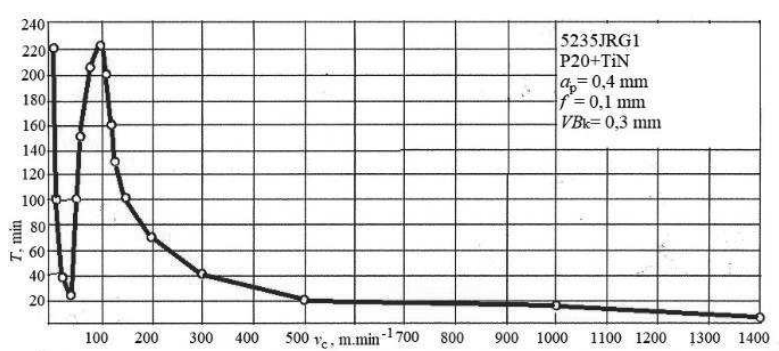

Fig. 11 Experimental dependence $T-v_{c}$ obtained in extreme range of cutting speeds

Let us return to dependence $R z-v_{c}$. During a different experiment, microgeometry of the machined surface has been observed. Corresponding dependence is shown in Fig. 12.

$$
v_{c}=\left(\ln v_{c}\right) ; v \in(0, \infty) ; v_{c} \in(1, \infty) ; C=C\left(a_{p}, f, r_{\varepsilon}\right), C=50
$$

The non-linear function $T=\mathrm{f}\left(v_{\mathrm{c}}\right)$ depends on nonlinear parameters. It si possible to statistically analyse the following dependence based on performed $n$ experimental dependences of tool durability $T_{1}, T_{2}, \ldots T_{n}$ on cutting speed:

$$
T_{t}=T\left(v_{\mathrm{c}} \cdot \theta\right)+\varepsilon_{t}
$$

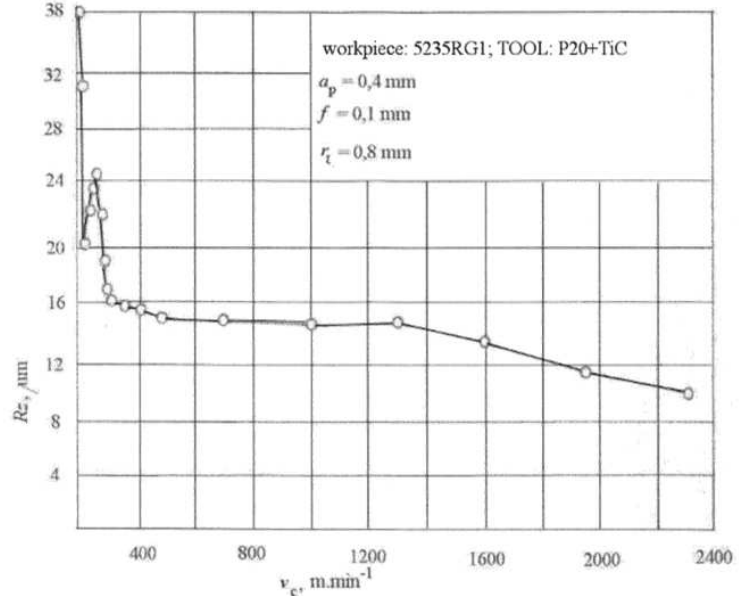

Fig. 12 Experimental dependence Rz- $v_{c}$ obtained in an extreme range of cutting speeds

The left part of the curve corresponds with Fig. 6 and 7. After reaching the cutting speed of around 400 $\mathrm{m} . \mathrm{min}^{-1}, \mathrm{R}_{z}$ decreases continually, which is positive. It presents a question, however, if the benefit of the improvement of machined surface quality at those cutting speeds is worth to lose the tool durability so fast (Fig. 11).

When dependences from Fig. 11 and 12 are compared, an opinion about the maximum usable cutting speed can be stated. When machining used steels, the best value presented is $v_{\text {cmax }}=400 \mathrm{~m} \cdot \mathrm{min}^{-1}$.

\section{Analytical expression of general depend- ence between cutting conditions and re- sults of machining}

As it follows the presented dependence diagrammes $F-v_{c}, R z-v_{c}, T-v_{c}$, their course is identical therefore it is possible to create their common analytical expression.

Let us try to derive the equation of curve $T=\mathrm{f}\left(v_{\mathrm{c}}\right)$.

Mathematical model of such dependence is nonlinear :

$$
T=C \cdot \exp (-v) \cdot\left(\left(v^{4}\right)+\left(v^{-1}\right)\right)
$$

where

where $\theta=\left(\theta_{1}, \ldots \theta_{p}\right)^{t} ; \theta \in R^{\mathrm{p}}$ is a vector of suggested parameters.

Cutting speed $v_{\mathrm{c}}$ is expressed by a single-column vector;

$\varepsilon_{1}$ is required precision: $\varepsilon_{\mathrm{t}}=N\left(0, \sigma^{2}\right)$.

$t=1, \ldots \mathrm{n}$, partial derivations $\frac{\partial^{2} \theta}{\partial \theta_{\mathrm{i}} \cdot \partial \theta_{\mathrm{j}}} \cdot t=1, \ldots \mathrm{n}$ are 
analogue functions.

The original relation is expressed in the following form:

$$
T=\frac{\ln v_{\mathrm{c}}^{4}+\frac{1}{\ln v_{\mathrm{c}}}}{e^{\ln v_{c}}} .
$$

Its graphic expression is shown in Fig. 12.

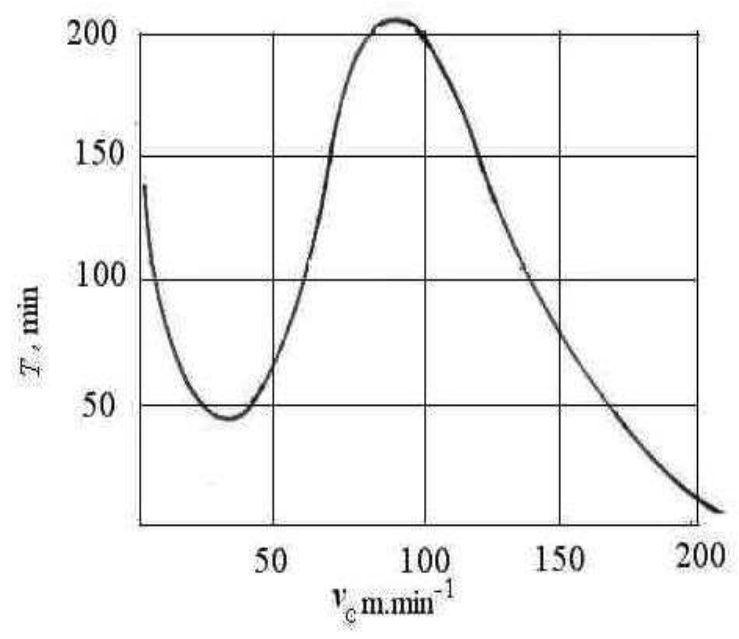

Fig. 13 Diagramme $T=f\left(v_{c}\right)$ from analytic expression (conditions identical to Fig. 5.2)

$$
50 \cdot \ln \left(v_{c}\right)+50 \cdot v_{c} \cdot \ln \left(v_{c}\right)-200 \cdot \ln \left(v_{c}\right)+50+v_{c} \cdot \ln \left(v_{c}\right)=0
$$

The equation has two solutions: $v_{\mathrm{copt}}=100 \mathrm{~m} \cdot \mathrm{min}^{-}$ ${ }^{1}$ and $v_{\mathrm{c} \min }=22 \mathrm{~m} \cdot \mathrm{min}^{-1}$. The first one corresponds with the maximum, the second one with the minimum (uninteresting) durability.

\section{Conclusion}

The analysis of experimental dependences between the cutting conditions and results of machining leads to the suggestion to generalise this dependence and form a generalised „,machining curve“. This phenomenal term enables a new approach to the optimization of cutting conditions considering the output parameters in the process of metal machining. It has been proved that all partial dependence curves visually possess similar course, which enables to implement and practically use this term in the determination of optimal cutting conditions from the viewpoint of expected results of machining (quality of machined surface, tool durability, cutting forces and energy consumption spent on the machining process).

\section{Acknowledgement}

\section{„This work was supported by the Slovak Research and Development Agency under the Contract No. $A P V V-18-0316 "$}

It can be seen that at minimal values of cutting speeds, the durability increases as a result of a small area of contact of the chip with the tool face. Cut material is firm but brittle. A segmented chip is formed, which does not have any adhesion with cutting material. At higher cutting speed the durability decreases (it has a local minimum at approximately $v_{c} \approx 20$ $\left.\mathrm{m} . \mathrm{min}^{-1}\right)$. Further increase in cutting speed leads to the formation of a built-up edge and has a protective effect on the cutting wedge. Durability increases sharply and reaches its maximum at approximately $\mathrm{v}_{\mathrm{c}}=90$ $\mathrm{m} . \mathrm{min}^{-1}$. Next, it decreases continually and at cutting speeds above $200 \mathrm{~m} \cdot \mathrm{min}^{-1}$ it reaches a value of several minutes.

Optimal cutting speed can be determined by a derivation of the equation (6.3) according to $\mathrm{v}_{\mathrm{c}}$ or its adjustment (6.3a) and formation of a derivation equal to -1 , i.e. construction of a tangent line to the curve under the angle $-45^{\circ}$.

$$
\begin{gathered}
T=\frac{50}{e^{\ln v_{c}}}\left(\left(\ln v_{c}\right)^{4}+\left(\ln v_{c}\right)^{-1}\right) \\
\frac{d T}{d v_{c}}=-1
\end{gathered}
$$

After the adjustment, the following equation is being solved:

\section{References}

[1] BABAK, S., POPOV, A (2017). The effect of the tool wear on the correlation of forces on the face and flank surfaces of the cutting tool. In: Manufacturing Technology, Vol. 17, No. 3, pp. 283287.

[2] CYKLIS, J.: (2001) Application of the Model for the Simulation of Discrete production Systems. ASME, 3, 1985, pp.33-45

[3] KALPAKJIAN, S.: (2001) Manufacturing Engineering and Technology. Prentice Hall, New Yersey, 2001, 1145 p.

[4] KOLAR, P et al. (2016) Cutting force modeling with a combined influence of tool wear and tool geometry. In: Manufacturing Technology, Vol 16, No. 3, pp. 524-531.

[5] KOVAČ, P., MIKILIČ, D.: (1998) Rezanje metala. Univerzitet v Novom Sadu, 1998 p. ISBN 86-899-40015-1

[6] KUNDRAK, J et al.: (2018) Analysis of the effect of chip size ratio and cutting forces in face milling for various cutting speeds. In: Manufacturing Technology, 2018, vol. 1, No. 3, pp. 431-438 
[7] LAMIT, L. G.: (1999) Technical Draving in Design. New York, West Publishing Company, 1999, $944 \mathrm{p}$.

[8] NESLUŠAN, M., ČILLIKOVÁ, M., MIČIETOVÁ, A. et al.: (2018) Influence of tool wear on surface after turning stainless steels. Manufacturing Technology, Vol 18, No. 5, pp.793-798
[9] TLUSTÝ, J.: (1993) High Speed Machining. Annals of the CIRP, 1993, Vol. 45, pp. 56-59

[10] VASILKO, K., MÁDL, J.: (2012) Teorie obrábèní. Univerzita J.E. Porkyně Ústí n. Labem, ISBN 978-80-7414-460-8

[11] WECK, M., et al.: (1993) Offent NC Systems, Grundlage Herstellerudabhängiger Flexibilität. VDI-Zeischrift, 135, 1993 